\title{
Learning effectiveness of nurses caring for patients with pulmonary artery catheters using e-learning and simulation approaches
}

\author{
Pei-Ching Ngu ${ }^{1,2}$, Yu-Hsiu Kao ${ }^{* 2}$, Hui-Ling Lin ${ }^{3}$, Heng-Ching Lin ${ }^{4}$ \\ ${ }^{1}$ Department of Nursing, Medical Intensive Care Unit, Sijhih Cathay General Hospital, New Taipei City, Taiwan \\ ${ }^{2}$ Graduate Institute of Health Allied Education, National Taipei University of Nursing and Health Sciences, Taiwan \\ ${ }^{3}$ Chang-Gung Memorial Hospital at Linkou, Taiwan \\ ${ }^{4}$ Shuang Ho Hospital, Ministry of Health and Welfare, Taiwan
}

Received: December 22, 2015

DOI: $10.5430 /$ jnep.v6n8p 74
Accepted: February 29, 2016

Online Published: March 31, 2016

\begin{abstract}
Background: A systematic training program has not been developed for pulmonary artery catheter (PAC) patient care in Taiwan; only the mentor-apprentice learning approach is used. Therefore, it is difficult for nursing personnel to maintain mastery of care.

Methods: ICU nurse practitioners of regional teaching hospitals were enrolled in this study to perform pretest, post-test, and repeated measurements in order to examine the long-term learning effectiveness of this intervention. Before and after e-learning using the PAC Teaching DVD and high-tech simulation interventions, this study used scales to assess knowledge, attitude, technique inspection, and satisfaction with the PAC Teaching DVD to collect data.

Results: The differences in the posttest scores and repeated measurements in the areas of knowledge and techniques of PAC patient care reached significance $(p<.05)$. The differences in scores in the care attitude areas of "Beneficial to the improvement of self-confidence in care" and "I believe that I can provide accurate data for decision-making" post-test and those in the area of "During insertion of a pulmonary artery catheter in patients, I will look up information to look for answers" reached significance $(p<.05)$. The learners were all satisfied with the PAC Teaching DVD.

Conclusion: This study considered the needs of learners, and developed the PAC Teaching DVD according to theory. The results showed that the interventions had a long-term learning effectiveness in terms of knowledge, attitude, and techniques of PAC patient care. This research can be used as a reference for training in the care of PAC patients.
\end{abstract}

Key Words: E-learning, Pulmonary artery catheter, Nurses, Learning effectiveness

\section{INTRODUCTION}

According to the statistics regarding the top 10 leading causes of death published by the Ministry of Health and Welfare Taiwan in 2013, ${ }^{[1]}$ cardiac diseases have been in the top 2 leading causes of death over the past few years. The mor- tality rate of cardiac diseases has increased to $75.8 \%$. Apparently, under the influences of global population ageing, hectic lifestyles, and changes in dietary habits, treatment and cardiac diseases and patient care have become increasingly important. The pulmonary artery catheter (PAC) is an impor-

\footnotetext{
*Correspondence: Yu-Hsiu Kao; Email: yuhsiu@ntunhs.edu.tw; Address: Graduate Institute of Health Allied Education, National Taipei University of Nursing and Health Sciences, No.365, Mingde Rd., Beitou Dist., Taipei City 112, Taiwan.
} 
tant pipeline for assessing cardiac functions, and tends to be used as a tool for clinical treatment and decision-making. ${ }^{[2]}$ Due to the high invasiveness and complexity of the PAC, it is usually used in severe acute care units, such as cardiac intensive care units (ICU), anesthesia rooms, and cardiac catheterization laboratories for comprehensive monitoring of patients' central hemodynamics and assessment of cardiac functions. ${ }^{[3]}$ However, in recent years, issues concerning the safety and effectiveness of use of the PAC have been gradually raised and discussed. Frazier and Skinner ${ }^{[4]}$ reported that the hemodynamic data obtained from the PAC is very meaningful to inform clinical diagnoses and treatments. However, whether the measured hemodynamic data are accurate and can provide patients with substantial assistance are subject to changes in patients' complicated disease condition, as well as the accuracy of the knowledge and skills of healthcare personnel. Although some hospitals have used the noninvasive Pulse Contour Cardiac Output to the replace the PAC to monitor hemodynamics, the function of direct and constant monitoring of pulmonary artery pressure still cannot be replaced. Therefore, many hospitals continue using the PAC to monitor patients with severe cardiorespiratory illness.

As the PAC is an invasive catheter, there are potential risks associated with the procedure of PAC insertion and during its usage, including arrhythmia, pneumothorax, pulmonary artery rupture and thrombophlebitis. Therefore, health care workers should have the knowledge and skills to monitor the measurement of pulmonary artery pressure. ${ }^{[5,6]}$ At present, a systematic training course for in-service education in the care of patients with an indwelling PAC in Taiwan has not yet been developed. Some teaching hospitals implement traditional classroom teaching for 1-2 hours every 3 months, while most teaching hospitals only implement mentor-apprentice instruction by chance. In addition, because the frequency of patients' use of such a catheter is indeterminate, it is difficult for nursing personnel to maintain mastery of care, and a gap in care experience conveyance may be formed. Clinically, nursing personnel tend to experience patient safety issues while caring for patients with a PAC, including (1) being uncertain of the meaning of indwelling of the PAC in terms of patients' treatment; (2) inaccurate technique for measuring hemodynamic data; (3) wrong wound care approaches, which can lead to catheter slippage or infection. Moreover, the reform of the current medical system has caused nursing personnel shortages, leading to overtime and 24-hour shifts. Therefore, the working time of nursing personnel is usually in opposition to in-service education, leading to nursing personnel's low motivation to attend courses and a poor learning effectiveness. ${ }^{[7]}$ E-learning integrates elements such as interaction, texts, images, animations, and audio and video

Published by Sciedu Press messages to enable learners to choose their learning content and pace according to their own willingness and interest, as well as to develop a learning process that meets their own needs. ${ }^{[8]}$ The integration of a teaching DVD with high-tech can better increase nursing personnel's learning motivation and participation, and improve their learning effectiveness. ${ }^{[9]}$

Therefore, the purposes of this study were to develop an e-learning program that meets the needs of in-service training in PAC care for nursing personnel, provide a high-tech scenario simulation, and investigate the long-term learning effectiveness of nursing personnel's care knowledge, attitude, and skills in caring for patients with an indwelling PAC.

\subsection{Literature review}

\subsubsection{Knowledge and ability required by nurses caring for patients with an indwelling PAC}

The total length of the PAC is $110 \mathrm{~cm}$, and includes 5 branches extending to the end. The clinical data directly measured by the catheter include: (1) Right Atrium Pressure (RAP); (2) Pulmonary Artery Pressure (PAP); (3) Pulmonary Capillary Pressure; (4) Cardiac Output (CO); and Cardiac Index $(\mathrm{CI}) .{ }^{[2]}$ After doctors select a catheter puncture site, the catheter floats to the right heart with the blood flow and stays at the pulmonary artery to further obtain hemodynamic information. ${ }^{[10]}$ Nurses caring for patients with such an invasive and complicated indwelling central venous catheter should receive appropriate training to strengthen their ability to care for patients with an indwelling PAC, as well as to enable patients to obtain a better prognosis. ${ }^{[5]}$ Nursing personnel should understand the purpose of the indwelling of the catheter, the waveforms, and complications of the heart chambers and pulmonary artery, as well as be able to use clinical data to engage in further treatment actions. In terms of care techniques, nursing personnel must accurately measure hemodynamic data ${ }^{[5]}$ and prevent catheter-related bloodstream infections.

Nursing personnel cannot accurately assist medical personnel in diagnosing diseases, guiding treatment alternatives, or assessing the effect of interventional treatment until they understand the purpose of indwelling of the PAC and the meaning of the measured data in terms of patients' treatment. When nursing personnel encounter patients with both congestive heart failure and hypoperfusion, they can use the clinical data measured by the PAC to provide patients with adequate amounts of water and adjust the dosages of vasopressors/antihypertensive drugs and cardiac stimulants. ${ }^{[11]}$ In addition, the accuracy of catheter positioning cannot be determined, and nursing personnel cannot assist in assessing sudden abnormalities of heart and lung functions until they understand the heart chambers and waveforms of the 
pulmonary artery. ${ }^{[5]}$ Moreover, nursing personnel must understand the potential complications caused by inaccurate care techniques, including the potential risks of indwelling and the indwelling period, such as catheter-related infections, thrombotic events, arrhythmias, and catheter knotting. The most severe scenarios are cardiac rupture, pulmonary artery rupture, and cardiac tamponade, which may undermine the safety and life of patients. ${ }^{[12]}$ Nursing personnel cannot carry out nursing activities that are meaningful to patients until they understand how hemodynamic data are applied to clinical treatments. ${ }^{[5]}$ Furthermore, the accuracy of the clinical data obtained from nursing personnel's catheter measurement technique is another factor affecting their provision of substantial assistance to patients. ${ }^{[4]}$ The prevention of catheter-related bloodstream infections (CRBSI) is the primary objective during the care process. In the case of CRBSIs, a patient's stay may be prolonged, medical cost may be increased, and patients suffering from severe symptoms may even pass away. Based on the above, nursing personnel should acquire the knowledge and ability to care for patients with an indwelling PAC to enable patients to receive care in a safe medical environment.

\subsubsection{Theories of design and application of e-learning}

The e-learning program for care of patients with a PAC in this study was designed based on information-processing theory and cognitive theory of multimedia learning. The illustrations and animations contained on the DVD can be visually received, while the voice-over and texts can be acoustically received. The teaching content can be chosen, organized, and actively processed by the brain to become image and language models, which can then be connected with operating memory and integrated with individuals' prior knowledge to enter long-term memory to improve learning effectiveness. ${ }^{[13]}$ E-learning emphasizes the exchange of "message-response-feedback" between people and machine to enable an interactive relationship between learners and computers to achieve individualization and adaptation, as well as to diagnose learning errors and deepen understanding. ${ }^{[14,15]}$ Moreover, e-learning concurrently considers the needs and characteristics of adult learning to combine complicated teaching content with multimedia to facilitate rapid learning of the whole brain, as well as to enable learners to discover new meanings of knowledge during their restructuring of experiences and changes in cognitive structure, and apply them to practical problem-solving. ${ }^{[16]}$

At present, teaching hospitals and nursing schools tend to incur a high cost for the purchasing of mannequins or the space and devices required by Objective Structured Clinical Examination (OSCE) to implement training plans. Many hospitals also use e-learning to implement in-service educa- tion. Although e-learning can reduce costs, there is a lack of diversified and interactive designs, and learning effectiveness is also uncertain. E-learning enables learners to flexibly choose a learning environment, adjust to their own learning pace, and view the key procedures and techniques repeatedly. Moreover, when used in combination with high-tech simulation for practical experience, it can integrate the teaching of cognitive and motor skills. ${ }^{[9]}$

\subsubsection{High-tech simulation}

A high-tech was developed based on situated cognition theory, which emphasizes that knowledge is the outcome of interactions between learners and the environment, and is affected by activities and social and cultural contexts. It suggests that learners should directly interact and coordinate with environments in actual scenarios or simulated actual scenarios to obtain actual knowledge. ${ }^{[17]}$ Therefore, in addition to providing e-learning for the care of pulmonary artery catheter patients, this study also used demonstration and scenario simulation to provide learners with opportunities for repeated practice to create the effect of learning transfer. As a result, learners can gradually learn the thinking process of experts through observations and practice. Thus, when they encounter actual emergencies and the treatment of patients with critical illnesses, they can implement effective and appropriate nursing techniques.

\section{METHODS}

\subsection{Research subjects and design}

This study enrolled nurse practitioners at the ICU of the Department of Internal Medicine and Department of Surgery in a certain regional teaching hospital as the research subjects. The inclusion criterion was: formal nurse practitioners who were willing to participate in the entire study and use the self-learning disc at least once. The exclusion criterion was: new nurse practitioners within the first 3 months of their probationary period.

This study used the single-group pretest and posttest design (including knowledge and attitudes, and skill assessment) and repeated measurements. The interventions included a self-learning DVD (referred to as the PAC Teaching DVD) and a high-tech simulation (referred to as the PAC Simulation), as well as the provision of mannequins and teaching tools for practice. This study performed the posttest 2 weeks later, and repeated measurements 3 months later. During this study, any in-service education regarding PAC patient care was not implemented. In addition, it was emphasized that the study results would only be used for research, and would not affect personal performance assessment. A total of 44 subjects were enrolled, and 12 subjects withdrew from the study early; therefore, there were 32 valid samples. 


\subsection{Research tools}

\subsubsection{Intervention scheme}

Before developing the intervention scheme, this study first assessed the learning needs of nursing personnel in the ICU. The results showed that nursing personnel require teaching media that they can actually operate and practice on, and that are convenient for learning. Therefore, the intervention scheme included the PAC Teaching DVD and PAC Simulation. The PAC Teaching DVD was developed according to relevant studies, ${ }^{[5]}$ clinical learning needs, the characteristics of adult learning, and information processing and cognitive theories of multimedia learning. The DVD included the following units: (1) understanding the purpose of indwelling of the catheter in patients; (2) understanding the heart chambers and waveforms of the pulmonary artery; (3) techniques for obtaining hemodynamic data; (4) application of clinical data to treatment; (5) understanding of complications; and (6) nursing techniques for the prevention of CRBSIs. All of the units included interactive Q\&A modules and invited feedback. All the nurse practitioners who participated in this study underwent pre-training tests, including assessment of their knowledge and attitudes, and skill assessment. They then had two weeks in which to watch the PAC Teaching DVD at work or at home. When they understood the content shown in the DVD, each individual was able to utilize the PAC Simulation in an independent ward of the ICU by using mannequins during a period of two weeks. The assessment of knowledge and attitude was based on a self-reported method, and skill assessment was performed by three senior nurses.

\subsubsection{Learning effectiveness assessment}

The content of the learning effectiveness assessment of the intervention scheme included the scales of knowledge, attitude, technique inspection, and satisfaction with the PAC Teaching DVD. The basic information of the research subjects included gender, age, educational background, level of nursing profession, total seniority of nursing work, seniority of ICU work, experience of e-learning for care of PAC patients, and classroom learning experience for care of PAC patients within the last three months.

Scale on knowledge of care of pulmonary artery catheter patients

This study referred to relevant domestic and foreign studies ${ }^{[5,18]}$ in order to develop this scale. The scale was mainly used to measure the accuracy of knowledge of nursing personnel in the ICU regarding care of pulmonary artery catheter patients. The scale included 6 dimensions: understanding the purpose of indwelling of the catheter in patients; understanding of heart chambers and waveforms of the pulmonary artery; techniques for obtaining hemodynamic data; applicaPublished by Sciedu Press tion of clinical data to treatment; understanding of complications; and nursing techniques for prevention of CRBSIs. Each dimension included 3 items, for a total of 18 items. If answered correctly, 1 point is given; if answered incorrectly or "I don't know", 0 is given. A higher score indicates that the knowledge of care of PAC patients is more accurate.

Scale on attitude towards care of pulmonary artery catheter patients

This study referred to relevant domestic and foreign studies ${ }^{[5,18,19]}$ in order to develop this scale. The scale was mainly used to measure nursing personnel's opinions on the care of PAC patients, and included 3 dimensions: faith, emotion, and action tendencies, for a total of 10 items. This study used a 4-point Likert scale, ranging from 4 (strongly agree) to 1 (strongly disagree). A higher score indicates that the attitude towards care of PAC patients is more positive.

Scale on technique inspection for care of pulmonary artery catheter patients

This study referred to relevant domestic and foreign studies $^{[5,20,21]}$ in order to develop this scale. The scale was mainly used to measure nursing personnel's implementation of techniques for care of pulmonary artery catheter patients in the ICU. The scale included the technique for obtaining hemodynamic data (including measurement of pulmonary capillary pressure, cardiac output, and cardiac index), and nursing techniques for the prevention of CRBSIs (including accurate implementation of nursing technique for changing the dressing at the puncture site). This study used a 2-point scale, 1 for accurate implementation of the technique, and 0 for non-implementation or inaccurate technique. A higher score indicates that the technique for care of PAC patients is more accurate.

\section{Scale on satisfaction with the PAC Teaching DVD}

This study referred to relevant domestic and foreign studies $^{[22,23]}$ in order to develop this scale. The scale was mainly used to measure nursing personnel's satisfaction with the PAC Teaching DVD. This study used a 4-point Likert scale, ranging from 4 (strongly agree) to 1 (strongly disagree). A higher score indicates that the satisfaction with the PAC Teaching DVD is higher.

\subsubsection{Reliability and validity tests of research tool}

For validity testing of the research tool, this study used expert content validity testing. Scholars of nursing education, experts in clinical nursing, and scholars of multimedia education were invited to complete the scale, a total of 5 experts. This study used a 4-point scale for scoring the PAC Teaching DVD and scale content, where 4 points and 1 point indi- 
cated "extremely correlated" and "extremely uncorrelated", respectively. This study used the Item-level Content Validity Index (I-CVI) to calculate and verify the validity. The results showed that the I-CVIs of the "multimedia self-learning disc" and "scale content" of this study were $0.96 \sim 1$. Scholars suggest that the acceptable I-CVI is $>0.80 .{ }^{[24]}$

For the reliability test, this study selected 24 nursing personnel at the ICU of the same hospital to undergo reliability testing. The results showed that the Kuder-Richardson formula 21 (KR-21) of the "scale of knowledge about care of PAC patients" was 0.748 , the internal consistency reliability coefficient (Cronbach's $\alpha$ ) of the "scale on attitude towards care of PAC patients" was 0.938, and the consistent correlation coefficient (Pearson) of the "scale on technique inspection for care of PAC patients" was 0.917, 1.00, and 0.878 for the three examiners, respectively.

\subsection{Research ethics}

This study enrolled research subjects following review and approval of the Institutional Review Board of the hospital (Approval Case No.: CGH-P102070). Based on the principle of "informed consent," the researcher explained the purposes and processes of this study in person, and conducted this study after obtaining the research subjects' informed consent to participate in this study. The research subjects were entitled to decide whether to participate in this study, and no one would be forced to participate.

\subsection{Data analysis}

This study used the computer statistics package software SPSS 19.0 for Windows to archive and analyze data, and employed methods such as distribution frequency, percentage, mean, standard deviation, paired $t$-test, and generalized estimating equations (GEE) to perform statistical analyses and present the research results.

\section{Results}

\subsection{Basic attributes of research subjects}

The basic attributes of the research subjects were as shown in Table 1. All of the research subjects were female, aged between 20 and 25 years. Most were university graduates, and their level of nursing profession was N1. The total seniority of their nursing work was mainly 1-5 years (Mean $=5.20$ years, $\mathrm{SD}=4.08$ years). The seniority of ICU work was mainly $1-5$ years (Mean $=4.38$ years, $\mathrm{SD}=3.45$ years $)$. Most had e-learning experience of care of pulmonary artery catheter patients; $81.3 \%$ did not have classroom learning experience of care of pulmonary artery catheter patients within the last 3 months.
Table 1. Distribution of Basic Information of the Research Subjects $(n=32)$

\begin{tabular}{|c|c|c|}
\hline Item & $\begin{array}{l}\text { Number of } \\
\text { subjects }\end{array}$ & Percentage(\%) \\
\hline \multicolumn{3}{|l|}{ Age (years) } \\
\hline $20-25$ & 16 & 50.0 \\
\hline $26-30$ & 9 & 28.1 \\
\hline $31-35$ & 4 & 12.5 \\
\hline$\geq 36$ & 3 & 9.4 \\
\hline \multicolumn{3}{|c|}{ Educational background (graduation) } \\
\hline Technical college or university & 22 & 68.8 \\
\hline Junior college & 10 & 31.2 \\
\hline \multicolumn{3}{|l|}{ Level of nursing profession } \\
\hline $\mathrm{N}$ & 13 & 40.6 \\
\hline N1 & 16 & 50.0 \\
\hline $\mathrm{N} 2$ & 2 & 6.3 \\
\hline N3 & 1 & 3.1 \\
\hline \multicolumn{3}{|l|}{ Total seniority of nursing work } \\
\hline $1-5$ years & 24 & 75.0 \\
\hline $6-10$ years & 4 & 12.5 \\
\hline$\geq 11$ years & 4 & 12.5 \\
\hline Mean \pm SD & $5.2 \pm 4.0$ & \\
\hline \multicolumn{3}{|l|}{ Seniority of ICU work } \\
\hline $1-5$ years & 26 & 81.3 \\
\hline $6-10$ years & 3 & 9.3 \\
\hline$\geq 11$ years & 3 & 9.4 \\
\hline Mean \pm SD & $4.3 \pm 3.4$ & \\
\hline \multicolumn{3}{|c|}{ E-learning experience of care of PAC patients } \\
\hline Yes & 11 & 34.4 \\
\hline No & 21 & 65.6 \\
\hline \multicolumn{3}{|c|}{ Classroom learning experience of care of PAC patients within the last } \\
\hline \multicolumn{3}{|l|}{3 months } \\
\hline Yes & 6 & 18.8 \\
\hline No & 26 & 81.2 \\
\hline
\end{tabular}

In order to understand the influence of previous e-learning experience of pulmonary artery catheter patient care, classroom learning experience within the last 3 months, and intervention effectiveness, this study performed statistical analyses (where no applicable subjects were excluded) on 21, 26, and 30 subjects, respectively. The results showed intervention effectiveness, suggesting that neither the implementation of e-learning nor classroom learning in the area of PAC patient care affected the statistical results of the intervention scheme. Therefore, this study performed statistical analyses on 32 subjects to reflect the research results.

\subsection{Analysis of the learning effectiveness of care of pac patients}

Tables 2 and 3 and Figures 1 and 3 show the effectiveness in the two dimensions (knowledge dimension and techniques dimension) of this study intervention. The posttest scores were all higher than the pretest scores, and the differences reached the level of significance. The repeated measurements also showed significant differences $(p<.05)$. Regarding the score of the scale on attitude, the posttest score and repeated

ISSN 1925-4040 E-ISSN 1925-4059 
measurements showed that only the differences in the scores of "I have sufficient self-confidence in caring for patients with an indwelling pulmonary artery catheter" in the "emotion" dimension $(t=-3.358, p<.05$; $\beta$ estimate $0.32, p<$ $.05)$ and that of "I believe that I can provide accurate clinical data from a pulmonary artery catheter for decision-making" in the "action tendencies" dimension $(t=-2.148, p<.05 ; \beta$ estimate $0.455, p<.05)$ reached statistical significance. In ad- dition, the score of "I'll look up information to seek solutions during care for patients with an indwelling pulmonary artery catheter" in the "action tendencies" dimension of repeated measurements ( $\beta$ estimate $0.626, p<.05$ ) reached a significant difference. However, the differences in the scores in the "faith" dimension and other items did not reach statistical significance (see Figure 2).

Table 2. Pre-and posttest Scores of Knowledge, Attitude, and Techniques Dimensions of PAC patient care $(\mathrm{n}=32)$

\begin{tabular}{|c|c|c|c|c|}
\hline \multirow{2}{*}{ Item } & \multirow{2}{*}{$\begin{array}{l}\text { Pretest } \\
\text { Mean } \pm \text { SD }\end{array}$} & \multicolumn{3}{|l|}{ Posttest } \\
\hline & & Mean \pm SD & Paired-t & $p$ \\
\hline \multicolumn{5}{|l|}{ Knowledge dimension } \\
\hline Purpose of indwelling of catheter in patients & $1.46 \pm 0.79$ & $2.61 \pm 0.68$ & -7.611 & $.000 * * *$ \\
\hline Heart chambers and waveforms of pulmonary artery & $1.50 \pm 0.82$ & $2.79 \pm 0.46$ & -9.244 & $.000 * * *$ \\
\hline Techniques for obtaining hemodynamic data & $1.80 \pm 0.76$ & $2.67 \pm 0.56$ & -5.784 & $.000 * * *$ \\
\hline Application of clinical data to treatment & $1.33 \pm 0.83$ & $2.56 \pm 0.66$ & -8.691 & $.000 * * *$ \\
\hline Understanding of complications & $1.85 \pm 0.83$ & $2.75 \pm 0.48$ & -6.624 & $.000 * * *$ \\
\hline Prevention of CRBSIs & $2.11 \pm 0.86$ & $2.68 \pm 0.51$ & -3.613 & $.001^{* *}$ \\
\hline \multicolumn{5}{|l|}{ Attitude dimension } \\
\hline $\begin{array}{l}\text { I have sufficient self-confidence in caring for patients with an } \\
\text { indwelling pulmonary artery catheter }\end{array}$ & $2.82 \pm 0.54$ & $3.18 \pm 0.54$ & -3.358 & $.002 *$ \\
\hline $\begin{array}{l}\text { I believe that I can provide accurate clinical data from a } \\
\text { pulmonary artery catheter for decision-making }\end{array}$ & $2.93 \pm 0.50$ & $3.14 \pm 0.51$ & -2.148 & $.037 *$ \\
\hline \multicolumn{5}{|l|}{ Techniques dimension } \\
\hline Techniques for obtaining hemodynamic data & $14.25 \pm 3.00$ & $22.65 \pm 2.82$ & -14.754 & $.000 * * *$ \\
\hline Prevention of CRBSIs & $6.23 \pm 2.25$ & $15.09 \pm 3.26$ & -15.109 & $.000 * * *$ \\
\hline
\end{tabular}

${ }^{*} p<0.05,{ }^{* *} p<0.01, * * * p<0.001$

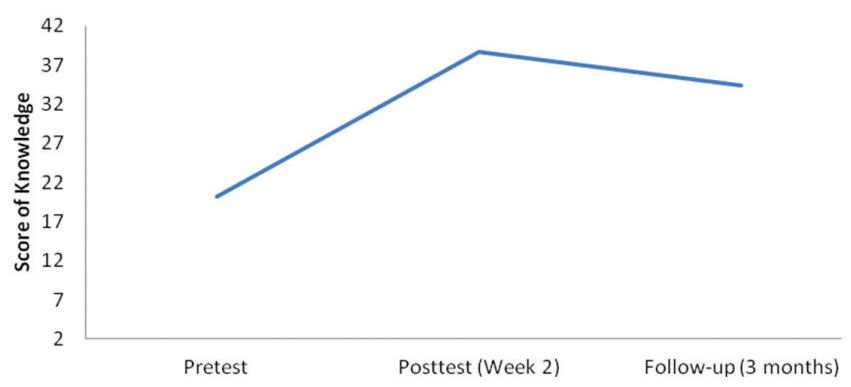

Figure 1. Long-term Follow-up of the Knowledge Dimension of Care for PAC Patients

\subsection{Satisfaction with learning using the PAC Teaching DVD}

The average number of times of learning of the research subjects was $2.23 \pm 1.25$ times, and the average self-learning time was $37.27 \pm 23.23$ minutes. Regarding satisfaction with the PAC Teaching DVD, $88.5 \%$ of the research subjects were satisfied or strongly satisfied. Most of the qualitative feed- back was positive, such as "Teaching content is beneficial to clinical practice"; "being able to flexibly choose a learning environment"; and "meeting learning needs and increasing learning effectiveness."

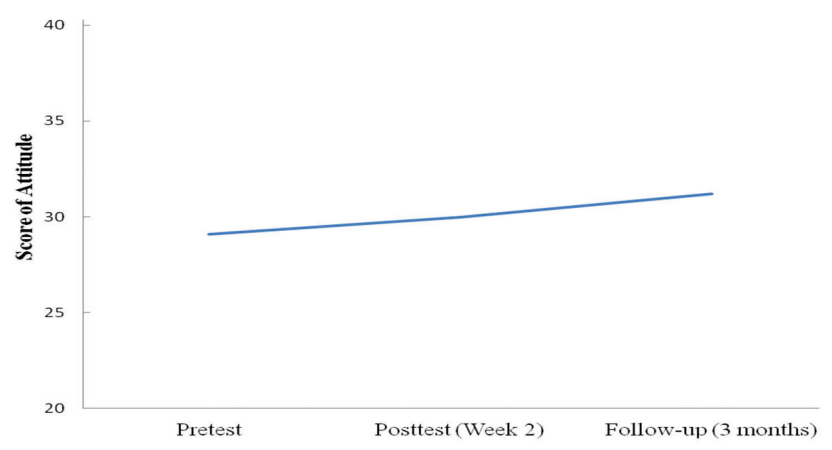

Figure 2. Long-term Follow-up of the Attitude Dimension of Care for PAC Patients 
Table 3. Repeated Measurements Scores of Knowledge, Attitude, and Techniques Dimensions of PAC patient care $(\mathrm{n}=32)$

\begin{tabular}{|c|c|c|c|}
\hline \multirow{2}{*}{ Item } & \multicolumn{3}{|c|}{ Repeated Measurements } \\
\hline & Estimate of $\beta$ & $95 \% \mathrm{CI}$ & GEE $(p)$ \\
\hline \multicolumn{4}{|l|}{ Knowledge dimension } \\
\hline Purpose of indwelling of catheter in patients & 0.461 & $0.305 \sim 0.618$ & $.000 * * *$ \\
\hline Heart chambers and waveforms of pulmonary artery & 0.397 & $0.275 \sim 0.519$ & $.000 * * *$ \\
\hline Techniques for obtaining hemodynamic data & 0.279 & $0.066 \sim 0.492$ & $.010^{*}$ \\
\hline Application of clinical data to treatment & 0.338 & $0.212 \sim 0.464$ & $.000 * * *$ \\
\hline Understanding of complications & 0.298 & $0.103 \sim 0.492$ & $.003^{* * *}$ \\
\hline Prevention of CRBSIs & -1.195 & $-0.222 \sim 0.222$ & 1.00 \\
\hline \multicolumn{4}{|l|}{ Attitude dimension } \\
\hline $\begin{array}{l}\text { I have sufficient self-confidence in caring for patients with an indwelling } \\
\text { pulmonary artery catheter }\end{array}$ & 0.320 & $0.287 \sim 0.564$ & $.000 * * *$ \\
\hline $\begin{array}{l}\text { I believe that I can provide accurate clinical data from the pulmonary artery } \\
\text { catheter for decision-making }\end{array}$ & 0.455 & $0.523 \sim 0.667$ & $.000 * * *$ \\
\hline $\begin{array}{l}\text { I’ll look up information to seek solutions during care for patients with an } \\
\text { indwelling pulmonary artery catheter }\end{array}$ & 0.626 & $0.340 \sim 0.686$ & $.000 * * *$ \\
\hline \multicolumn{4}{|l|}{ Techniques dimension } \\
\hline Techniques for obtaining hemodynamic data & 0.107 & $0.094 \sim 0.121$ & $.000 * * *$ \\
\hline Prevention of CRBSIs & 0.100 & $0.088 \sim 0.112$ & $.000 * * *$ \\
\hline
\end{tabular}

$* p<.05, * * * p<.001$

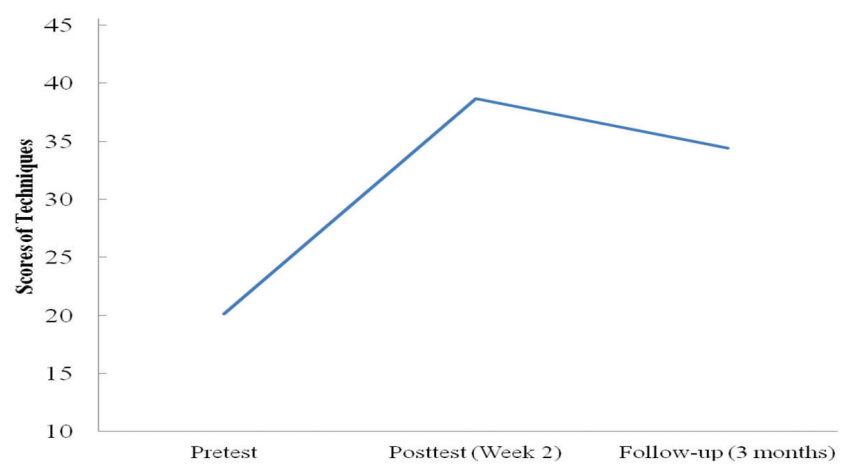

Figure 3. Long-term Follow-up of the Techniques Dimension of Care for PAC Patients

\section{Discussion}

4.1 Learning effectiveness in terms of knowledge, attitude, and techniques for care of pac patients

The PAC Teaching DVD developed in this study included units required to be studied by nursing personnel in order to care for patients with an indwelling PAC. This study developed an interesting interactive Q\&A module to attract learners' attention. Knowledge content is converted into image and language models in the brain, which are then connected with operating memory and integrated with individuals' prior knowledge in order to further improve learning effectiveness. Learners indicated in their feedback that "Clear and explicit images and animations are comprehensible and worthy of collection", "learners can engage in self-learning in order to better understand the principles of the PAC Teaching DVD", "Interactive disc enables learners to better understand the methods and principles of PAC patient care. Awesome!" The findings of our study were consistent with the study by Mayer and Moreno, ${ }^{[25]}$ indicating that multimedia can employ computer animation to convey, explain, and clarify incomprehensible cause-and-effect events to increase memorial retention and recall.

Cheng and $\mathrm{KaO}^{[26]}$ used traditional teaching and e-learning to investigate the learning effectiveness in terms of attitude towards care of cancer patients. The results showed that, although e-learning improved the overall attitude towards care of cancer patients, the difference did not reach the level of significance. This result was consistent with the result of this study. Guo et al. ${ }^{[27]}$ found that the effectiveness of intervention of health education and behavioral science on changes in the knowledge dimension was most significant, but it only had a mild effect on changes in attitude. The reason for this might be that students are used to instant and structured teaching in front of them. In addition, because there is interaction with teachers, expression of body language, and flexible and instant meaning conveyance during courses, ${ }^{[28]}$ students can form social interactions during teaching. Social interactions have a significant influence on the improvement of learning attitude and work morale. ${ }^{[29]}$ On the other hand, the pretest score of the scale on attitude was slightly higher, suggesting 
that nursing personnel had developed an accurate attitude towards care of pulmonary artery catheter patients in the ICU. Moreover, self-confidence is an important predictor of learning effectiveness. ${ }^{[30]}$ The learning attitude assessment in this study showed that the differences in scores for "I have sufficient self-confidence in caring for patients with an indwelling PAC," "I believe that I can provide accurate clinical data from the PAC for decision-making," and "I'll look up information to seek solutions during care for patients with an indwelling PAC" reached significance. Therefore, long-term learning effectiveness in the knowledge and techniques dimensions was generated. This result is consistent with that of the study by Chiang and colleagues, ${ }^{[31]}$ in which qualitative interviews were used to understand the effectiveness of nursing personnel's use of a multimedia interactive teaching disc in order to learn the techniques of disability assessment. The results verified that the multimedia interactive teaching disc could indeed increase nursing personnel's self-confidence. The demonstration videos might clarify their inconsistent and vague concepts to improve their self-confidence in care and further achieve learning effectiveness.

The core nursing techniques for patients with an indwelling PAC are measurement of pulmonary capillary pressure, cardiac output and cardiac index, and change of wound dressing. Therefore, the use of the nursing techniques demonstration video on the e-learning disc enabled nursing personnel to obtain consistent care techniques to solve issues such as a low mastery of care and failure to receive in-service education due to shift pattern. The use of a Teaching DVD, in combination with high-tech simulation, strengthened nursing personnel's conversion of declarative knowledge into procedural knowledge, integrated teaching of cognitive and motor skills, increased nursing personnel's learning motivation and participation, and improved their learning effectiveness. ${ }^{[9]}$ This result was consistent with the learning pyramid theory. Video and audio teaching can only retain $10 \%-20 \%$ of the long-term learning effectiveness, while practical operation (simulation) can retain $75 \%$ of the long-term learning effectiveness. ${ }^{[32]}$ Most of the previous studies on PAC patient care training were based on video and audio teaching methods (DVD). In the current study, we used both DVD and simulation methods, which augmented the long-term learning effectiveness.

Kneebone and ApSimon ${ }^{[33]}$ requested teachers with different teaching styles to use the multimedia teaching disc to demonstrate surgical procedures, and provided simulation teaching tools to engage in practical practice. The research results showed that students obtained a comprehensive ability to implement techniques, and teachers' flexible teaching designs met the learning needs of different learners. Therefore, if teachers can apply appropriate teaching strategies to digital technology in different subjects and different environments, multiple learning outcomes can be generated. ${ }^{[34]}$

\subsection{Satisfaction with Learning from the PAC Teaching DVD}

Regarding the order of items in the scale of satisfaction with learning, the 4 items with the highest scores were: "Teaching content is beneficial to clinical practice," "This self-learning disc enables learners to flexibly choose a learning environment," "This self-learning disc meets my learning needs," and "This self-learning disc can increase learning effectiveness." The reason might be that there is a lack of in-service education in relevant topics and opportunities for practical operation in hospitals. In addition, nursing personnel's shift system usually makes it difficult to attend courses. The teaching methods of the Teaching DVD and high-tech simulation meet individual learning needs and further improve learning effectiveness.

\subsection{Research limitations}

Due to limitations of time, labor, and funds, this study enrolled 50 nursing personnel at the ICU of the Department of Internal Medicine and Department of Surgery of a certain regional teaching hospital as the research subjects, and excluded those who withdrew from the study early; thus, only 32 subjects were enrolled. In addition, because the methods of caring for patients with an indwelling PAC in teaching hospitals at the same level are different, it was difficult to enroll nursing personnel with similar backgrounds as the control group. Therefore, a control group was not included in this study, and hence this study used repeated measurements to investigate the delayed learning effectiveness of research subjects.

In the present study, the tests for learning assessment were designed based on the teaching materials. Measurement of knowledge and attitude was via self-report, and therefore memory errors may have occurred. Skill assessment was completed by senior nurses and was more objective. Although three senior nurses discussed and reached an agreement on the scoring standard, subjectivity and bias may still have existed. In addition, satisfaction assessment only focused on the PAC Teaching DVD, which was only associated with the motivation of the students, but independent of the effectiveness of learning. These factors constitute limitations of this study. Moreover, due to limitation of funds, the researcher personally filmed and produced the content of the PAC Teaching DVD in this study. As a result, the video editing and sound control need to be improved. 


\section{Conclusion}

The intervention scheme in this study was designed based on information-processing theory, cognitive theory of multimedia learning, and clinical assessment needs. The content included a PAC Teaching DVD and high-tech PAC Simulation, which generated significant long-term learning effectiveness in terms of knowledge and techniques for the care of PAC patients. Nursing personnel are advised to engage in simulation in combination with the use of the Teaching DVD during in-service training.

Future suggestions for research involve using the DVD only, and then the DVD with simulation, in order to compare learning outcomes. A control group of nursing personnel in different areas, and in hospitals at different levels, should be included in order to increase the persuasiveness of the research results. All the subjects in this study were adults. Adult learning is inclined to be self-oriented. It is advised that the "scale of preparation for self-oriented learning" is used in studies of the effectiveness of the PAC Teaching DVD where the subjects are nursing personnel (excluding subjects with self-learning disabilities), and investigation of intervention effectiveness should be facilitated. Moreover, future studies are advised to commission professionals to design a DVD in order to improve the quality of the self-learning disc.

\section{REFERENCES}

[1] Ministry of Health and Welfare, 2013 statistics of causes of death 2014. http://www.mohw.gov.tw/EN/Ministry/Statistic_ P. aspx?f_list_no $=474 \&$ fod_list_no $=5045 \& d o c \_n o=45981$. Accessed Apr. 15, 2015.

[2] Ramos CC, Dal Sasso GT, Martins CR, et al. Invasive hemodynamic monitoring at bedside: nursing evaluation and nursing care protocol Rev Esc Enferm USP. 2008; 42: 512-518.

[3] Scales K, Collie E. A practical guide to using pulmonary artery catheters. Nurs Stand. 2007; 21: 42-48. http://dx. doi .org/10. $7748 / \mathrm{ns} 2007.07 .21 .43 .42 . \mathrm{c} 4577$

[4] Frazier SK, Skinner GJ. Pulmonary artery catheters: state of the controversy. J Cardiovasc Nurs. 2008; 23: 113-121. PMid:18382253. ht tp://dx.doi.org/10.1097/01. JCN.0000305073.49613.db

[5] Cisar NS, Caruso EM, Hess GM, et al. Changing the environment of care for patients with a pulmonary artery catheter. Crit Care Nurse. 2010; 30: 34-44.

[6] Chang MY, Liu HL. Practical Critical Care Nursing. 2nd ed. Taipei City: Wunan. 2011.

[7] Lin MH, Liu CG, Sheng MH, et al. Case studying the personal experiences of e-Learning courseware production for nursing clinical ladder training in a hospital. T.S.M.H Medical \& Nursing Journal. 2009; 15: 69-80.

[8] Shiue YM, Hsu YC. The effects of self-regulated learning strategy and different levels of learner control on achievement in a hypermedia learning environment. Chia-Nan Annual Bulletin. 2005; 31: 345-360.

[9] Hou SY, Chang CW, Hsieh SL. Improving the accuracy of caregiverprovided in-home total parenteral nutrition care. The Journal of Nursing. $2014 ; 61: 33-40$

[10] Epping K, Hammer B. Removal of a pulmonary artery catheter in the presence of implanted leads. Crit Care Nurse. 2012; 32: 69-71. PMid:22855081. http://dx.doi .org/10.4037/ccn2012339

[11] Toumpaniaris P, Skalkidis I, Nikolakopoulos I, et al. Modeling and simulation of right ventricular volume measurement system during right heart catheterization. J Med Syst. 2012; 36: 615620. PMid:20703672. http://dx.doi .org/10.1007/s10916-0 10-9525-9

[12] Karahan N, Yetkin U, Takut N, et al. Approach to Swan Ganz thermodilution catheter complications: 6 years experience with 2310 cases. Internet J Thorac Cardiovasc Surg. 2008; 11: 20.
[13] Mayer RE. Multimedia learning 2nd ed. Cambridge, UK: Cambridge University Press. 2009.

[14] Kao CC, Tang SH, Chan MH. Design of interactive-learning System. Journal of National University of Tainan. 2005; 39: 111-132.

[15] Sales GC. Designing feedback for CBI: matching feedback to the learner and learner outcomes. Computers in the Schools. 1988; 5: 225-240. http://dx.doi.org/10.1300/J025v05n01_21

[16] McCombs BL, Vakili D. A learner-centered framework for e-learning. Teachers College Record. 2005; 107: 1582-1600. http://dx.doi . org/10.1111/j.1467-9620.2005.00534.x

[17] Schunk DH. Constructivism. In: Schunk, D. H., ed. Learning theories: An educational perspective. 6th ed. Boston, MA: Pearson; 2012 p. 233-234.

[18] Chen YY, Chou P. Pulmonary artery catheter infection caused by risk factors and protective measures. Nosocomial Infection Control Journal. 2002; 12: 44-51.

[19] Chen LH. Attitudes and change of attitude. 2011

[20] Lin GM, Lee MM, Lin HC, et al. Medical-surgical nursing techniques. 7th ed. Taipei City, Taiwan: Farseeing. 2009.

[21] Weigand DL. AACN procedure manual for critical care 6th ed. Philadelphia, PA: Saunders. 2010.

[22] Champion VL, Springston JK, Zollinger TW, et al. Comparison of three interventions to increase mammography screening in low income African American women. Cancer Detect Prev. 2006; 30: 535-544. PMid:17110056. http://dx.doi.org/10.1016/j.cdp .2006 .10 .003

[23] Lin IH, Yeh ML, Chen HH, et al. Efficacy of a self-study multimedia program in Chinese medicine nursing. The Journal of Health Science. 2006; 8: 169-176.

[24] Polit DF, Beck CT. Nursing Reseach-Generating Assessing Evidence for Nursing Practice 9th ed. Philadelphia, PA: Lippincott Williams \& Wilkins. 2012.

[25] Mayer RE, Moreno R. Nine ways to reduce cognitive load in multimedia learning. Educational psychologist. 2003; 38: 43-52. http://dx.doi.org/10.1207/S15326985EP3801_6

[26] Cheng YJ, Kao YH. Cancer nursing care education programs: the effectiveness of different teaching methods. The Journal of Nursing. 2012; 59: 38-48. PMid:23034546.

[27] Guo JL, Husng CM, Su FC, et al. The meta-analysis of the effects of intervention studies using health education and behavioral modification. Journal of Health Education. 2003; 20: 71-88. 
[28] Su YC, Ko HK, Liu YY. A comparative analysis of traditional classroom lecturing and E-learning from the learner's perspective. The Kaohsiung Journal of Nursing. 2008; 25: 8-21.

[29] Månsson J, Dahlander J. Social interaction impact on attitudes: Native Swedes' attitudes towards labour immigrants and guest workers after hurricane Gudrun. Baltic Journal of Economics. 2011; 11: 5164. http://dx.doi.org/10.1080/1406099X.2011.10840490

[30] Kuo MC, Lee SF. Exploration of factors related to learning attitude and learning outcome among nursing students in physical examination skills course. Chang Gung Nursing. 2008; 19: 172-186.
[31] Chiang HC, Lin FY, Hwu YJ. Disability assessment: the efficacy of multimedia interactive nurse education. J Nurs Res. 2013; 21: 8393. PMid:23681345. http://dx.doi.org/10.1097/jnr.0b013 e3182921f5a

[32] Lalley JP, Miller RH. The learning pyramid: Does it point teachers in the right direction? Education. 2007; 128: 64-79.

[33] Kneebone R, ApSimon D. Surgical skills training: simulation and multimedia combined. Med Educ. 2011; 35: 909-915.

[34] Chen YT. The study on the combination of teaching strategy for examining learning performance. Journal of Tainan University of Technology. 2010; 29: 191-211. 